\title{
Structure-based Identification of a Ricin Inhibitor
}

\author{
Xinjian Yan', Thomas Hollis', Maria Svinth', Philip Day ${ }^{1}$ \\ Arthur F. Monzingo', George W. A. Milne ${ }^{2}$ and Jon D. Robertus ${ }^{1 *}$
}

${ }^{1}$ Department of Chemistry and Biochemistry, University of Texas, Austin, TX, 78712, USA

${ }^{2}$ Laboratory of Medicinal Chemistry, National Institutes of Health, Bethesda, MD 20892, USA
Ricin is a potent cytotoxin which has been used widely in the construction of therapeutic agents such as immunotoxins. Recently it has been used by governments and underground groups as a poison. There is interest in identifying and designing effective inhibitors of the ricin A chain (RTA). In this study computer-assisted searches indicated that pterins might bind in the RTA active site which normally recognizes a specific adenine base on rRNA. Kinetic assays showed that pteroic acid could inhibit RTA activity with an apparent $K_{\mathrm{i}}$ of $0.6 \mathrm{mM}$. A $2.3 \AA$ crystal structure of the complex revealed the mode of binding. The pterin ring displaces Tyr80 and binds in the adenine pocket making specific hydrogen bonds to active site residues. The benzoate moiety of pteroic acid binds on the opposite side of Tyr80 making van der Waals contact with the Tyr ring and forming a hydrogen bond with Asn78. Neopterin, a propane triol derivative of pterin, also binds to RTA as revealed by the Xray structure of its complex with RTA. Neither pterin-6-carboxylic acid nor folic acid bind to the crystal or act as inhibitors. The models observed suggest alterations to the pterin moiety which may produce more potent and specific RTA inhibitors.

(C) 1997 Academic Press Limited

Keywords: ricin; inhibitor; X-ray structure; pteroic acid; neopterin

\section{Introduction}

Ricin is a potent heterodimeric cytotoxin easily isolated from the seeds of the castor plant, Ricinus communis. The protein consists of a lectin B chain, which can bind cell surfaces, and an A chain (RTA) which enzymatically depurinates a key adenine residue in $28 \mathrm{~S}$ rRNA (Endo \& Tsurugi, 1987). Ricin has an $\mathrm{LD}_{50}$ of $\sim 1 \mu \mathrm{g} / \mathrm{kg}$ body weight for mice, rats, and dogs, and is ten times more potent against rabbits (Olsnes \& Pihl, 1982). The toxic dose for humans is likely to be in the $\mu \mathrm{g} / \mathrm{kg}$ range and ranks it among the most toxic substances known. The protein has been used extensively in the design of therapeutic immunotoxins. In these constructs, ricin, RTA, or a related toxin is chemically or genetically linked to an antibody to form a "magic bullet" which can preferentially target those cell lines carrying antigenic markers recognized by the antibody (Frankel, 1988).

Ricin has also been used as a poison agent. The protein gained notoriety when it was used in the famous "umbrella tip" assassination of Georgy Markov (Rich, 1992) and was also used in an un-

Abbreviations used: RTA, ricin A chain; FMP, formycin monophosphate; PTA, pteroic acid. successful attempt to poison the famous Soviet dissident Alexander Solzhenitsyn (Remnick, 1992). Recently, ricin was prepared by a militant anti-tax group which planned to poison IRS personnel; they were arrested and convicted of the crime (de Fiebre, 1995).

There is interest, given the above, to identify or design potent inhibitors of ricin. These could, in principle, be used to facilitate immunotoxin treatment by helping to control non-specific cytotoxicity, or could be used as antidotes to poison attacks. Recently there has been interest in structure-based drug design, that is using the knowledge of protein structure to identify enzyme inhibitors. The most common paradigm for this overall process has been called an "iterative protein crystallographic algorithm" by Appelt et al. (1991) in a paper describing the design of inhibitors for thymidylate synthase. The main idea is that the protein active site is used as a template to design or to identify complementary ligands. These are then ranked, and tested kinetically. Promising inhibitor candidates are then bound to the protein target and analyzed crystallographically for comparison with the proposed model. Alterations are made in the inhibitor which should improve binding and a new round of tests is carried out. 
A number of laboratories have used variations of this protocol to design efficacious inhibitors. For example, the search program DOCK (Kuntz et al., 1982) has been used to predict that the known anti-psychotic drug haloperidol would bind to the human immunodeficiency virus (HIV) protease (DesJarlais et al., 1990). Crystallographic studies, together with computer-aided search methods, were also used in the design of inhibitors of purine nucleoside phosphorylase (Ealick et al., 1991). The program GRID (Goodford, 1985) has been used to design two very successful inhibitors of influenza virus neuraminidase (von Itzstein et al., 1993). Chemical substitutions to the sialic acid substrate were predicted to be energetically favorable, based on likely interactions with the known X-ray structure of the enzyme; subsequent binding assays revealed $K_{\mathrm{i}}$ values as low as $0.2 \mathrm{nM}$. These compounds not only inhibited neuraminidase but retarded viral replication in cultured cell and animal models as well.

The X-ray structure of ricin has been solved (Montfort et al., 1987), refined to $2.5 \AA$ (Rutenber et al., 1991), and described in detail (Katzin et al., 1991; Rutenber \& Robertus, 1991). The structure of RTA expressed in Escherichia coli has also been solved to $2.3 \AA$ resolution for monoclinic crystals (Mlsna et al., 1993) and recently to $1.8 \AA$ resolution for a tetragonal form (Weston et al., 1994). The crystal structures of two substrate analogs, formycin monophosphate (FMP) and the dinucleotide ApG, have also been analyzed bound to ricin A chain (Monzingo \& Robertus, 1992).

The X-ray model allowed identification of a number of amino acid residues which were hypothesized to be important for RTA substrate binding and for the depurination mechanism; these include Glu177, Arg180, Trp211, Tyr80 and Tyr123. Site-directed mutagenesis of the cloned RTA gene has been used to examine the relative significance of these residues (Schlossmann et al., 1989; Frankel et al., 1990; Ready et al., 1991; Kim \& Robertus, 1992). Several closely related mechanisms of action have been proposed which incorporate elements of the structural and kinetic analyses (Monzingo \& Robertus, 1992; Ren et al., 1994; Huang et al., 1995). It is likely that the susceptible adenine base binds between tyrosine residues 80 and 123 while forming specific hydrogen bonds with the backbone carbonyl group and amido nitrogen atom of Val81 and with the carbonyl group of Gly121. In the hydrolysis, the leaving adenine is at least partially protonated by Arg180, and Glu177 may stabilize a putative oxycarbonium transition state or, more likely, act as a base to polarize the attacking water.

Until now, no inhibitors for RTA have been identified. Even FMP, which is known to bind RTA, is not an effective inhibitor of the enzyme. Here we report that the X-ray structure of RTA serves to define elements of the active site which can interact strongly with small molecules in a search for inhibitors. Pteroic acid (PTA) is seen to act as an in- hibitor for RTA and may serve as a lead compound for the development of more potent inhibitors.

\section{Results}

A query was constructed using the geometric and bonding parameters of the observed FMP ligand, and a search of the NCI data base was made with CHEMX. Among the compounds predicted to have hydrogen bond donors and acceptors in an orientation favorable for RTA interaction was the pterin derivative called pteroic acid (PTA). SYBYL calculations suggested that pteroic acid might bind better than FMP. Interaction enthalpies, calculated assuming one negative charge on each ligand, were $-106 \mathrm{kcal} /$ mole for pteroic acid, as compared with $-89 \mathrm{kcal} / \mathrm{mole}$ for FMP. It is important to note that the interaction enthalpies do not consider such terms as configurational entropy nor the effect of solvent interactions and so are not meant to represent the free energy of binding the ligand to the protein. The calculation is intended to serve as a rough guide to comparing the likely affinities of related compounds for the target enzyme.

To determine if pteroic acid was indeed an inhibitor of RTA, it was tested in a protein synthesis assay (see Materials and Methods); because of the limited solubility of pteroic acid, the experiments and controls were carried out at $\mathrm{pH}$ 9. Figure 1 shows protein synthesis on $300 \mathrm{nM}$ Artemia salina ribosomes in the presence of varying concentrations of pteroic acid, in the presence and absence of $1.5 \mathrm{nM}$ RTA. The Figure shows that pteroic acid has a minor inhibitory effect on protein synthesis itself; $1.7 \mathrm{mM}$ pteroic acid inhibits protein synthesis about $20 \%$. The inset panel replots the data as the fraction of possible RTA activity versus the concentration of pteroic acid. It shows that $0.6 \mathrm{mM}$ pteroic acid reduces RTA action by $50 \%$ and defines the effective $K_{\mathrm{i}}$ for the inhibitor.

Several efforts were made to crystallographically observe the binding of pteroic acid to RTA. The strongly diffracting tetragonal crystals were grown at $\mathrm{pH} 4.5$ and did not bind the inhibitor either by soaking in a saturated solution or by cocrystallization. Monoclinic crystals, at $\mathrm{pH} 9$, were made $20 \%$ saturated with pteroic acid and soaked for seven days. Although the crystals initially cracked, over the soaking time most of the cracks annealed. Diffraction showed that the complex was not isomorphous with the native. Native cell parameters are $a=42.6 \AA, b=68.1 \AA, c=50.2 \AA$ and $\beta=112.9^{\circ}$ (Robertus et al., 1987). The pteroic acid complex crystal has $a=39.0 \AA, b=64.4 \AA, c=49.4 \AA$ and $\beta=108.0^{\circ}$.

Three-dimensional data were collected to $2.3 \AA$ including 68,262 observations of 10,999 reflections; reflection intensities scaled with $R=6.5 \%$. Since the crystals were not isomorphous with the native, the RTA-PTA complex was solved using molecular replacement methods. The monoclinic RTA was used as a model for a rotation search using the program 


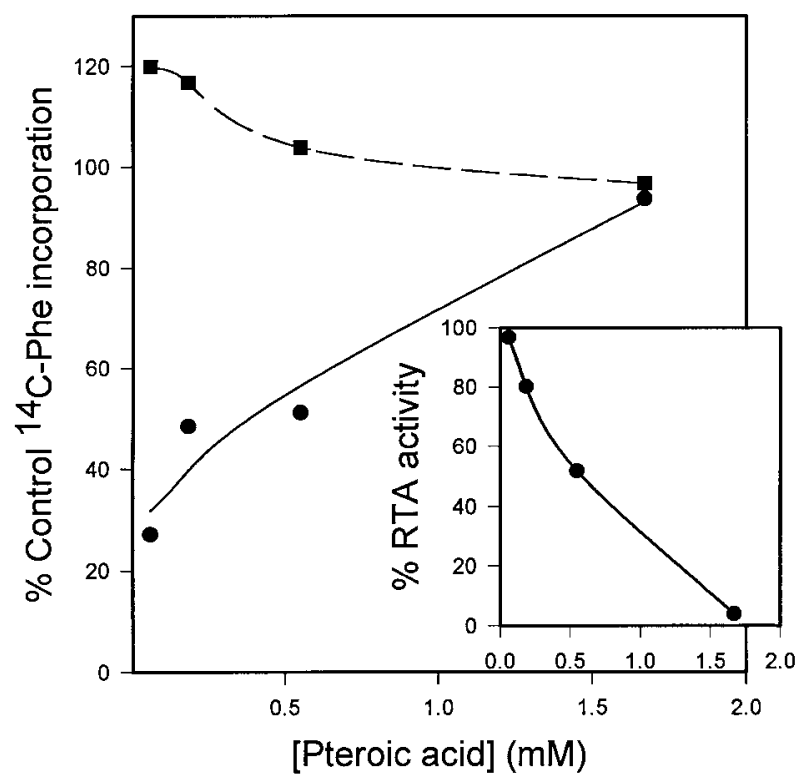

Figure 1. Inhibition of ricin A chain (RTA) by pteroic acid. Pteroic acid (squares) has a minor inhibitory effect on protein synthesis using Artemia salina ribosomes. Protein synthesis is reduced to about $20 \%$ in the presence of $1.5 \mathrm{nM}$ RTA (circles) but toxin action is inhibited by increasing doses of pteroic acid. The inset replots the level of RTA activity as a function of pteroic acid concentration.

X-PLOR (Brünger, 1988). Data between 10 and $4 \AA$ showed no rotation. A translation search was then executed with X-PLOR. It showed a translation of $0.65 \AA$ along $x$, and of $2.82 \AA$ along $z$. The initial positioning was completed using the rigid-body refinement option of X-PLOR; the $R$-factor to $3 \AA$ resolution was 0.36 .

A difference map with coefficients $\left(F_{o}-F_{c}\right)$ was calculated and showed a mixture of positive and negative peaks within the active site. These could be interpreted as the binding of PTA in the area previously seen to bind FMP. The pterin ring occupies the same site as the formycin ring of FMP or the adenine ring of the ApG dinucleotide. This requires that the Tyr80 side-chain rotates roughly $45^{\circ}$ to stack with the aromatic surface of the pterin, in a way similar to that seen for FMP (Monzingo \& Robertus, 1992). The Tyr80 position in the model was adjusted and a second $\left(F_{\mathrm{o}}-F_{\mathrm{c}}\right)$ map computed. This OMIT map is shown in Figure 2. There is clear electron density for the pterin moiety of the inhibitor; the benzoic acid density is weaker but still allows that group to be readily positioned. PTA was built into the density and the model subjected to four successive rounds of energy minimization and simulated annealing using X-PLOR. Between each round of refinement the resolution was increased by $0.2 \AA$ beginning at $3.0 \AA$ and ending at $2.3 \AA$. Another difference map was calculated and 45 water molecules were added to the structure. After a final round of energy minimization and isotropic temperature factor refinement a final $R$-factor of $17.9 \%$ was calculated for all data to $2.3 \AA$. Isotropic temperature factor refinement showed the pterin ring, with average $B$-values of 11 , was more rigidly held than the benzoic acid moiety where average $B$-values were 26 . The occupancy of the pteroic acid refined to 1.0 , as compared to 0.5 seen previously for FMP (Monzingo \& Robertus, 1992).

Following the analysis of PTA, structural and kinetic studies were carried out on a number of other pterin-based compounds, as shown in Table 1 . These differ essentially in the size of the group attached to pterin at position 6 .

Neopterin is pterin derivatized at position 6 with propane triol. It was observed in the protein synthesis assay to be a modest inhibitor of RTA, with a $K_{\mathrm{i}}>2 \mathrm{mM}$ (data not shown). Monoclinic crystals of an RTA complex were obtained by cocrystallization; they were isomorphous with the native, and diffracted to $2.5 \AA$ resolution. A total of $58,838 \mathrm{ob}$ servations of 9030 reflections to $2.5 \AA$ resolution
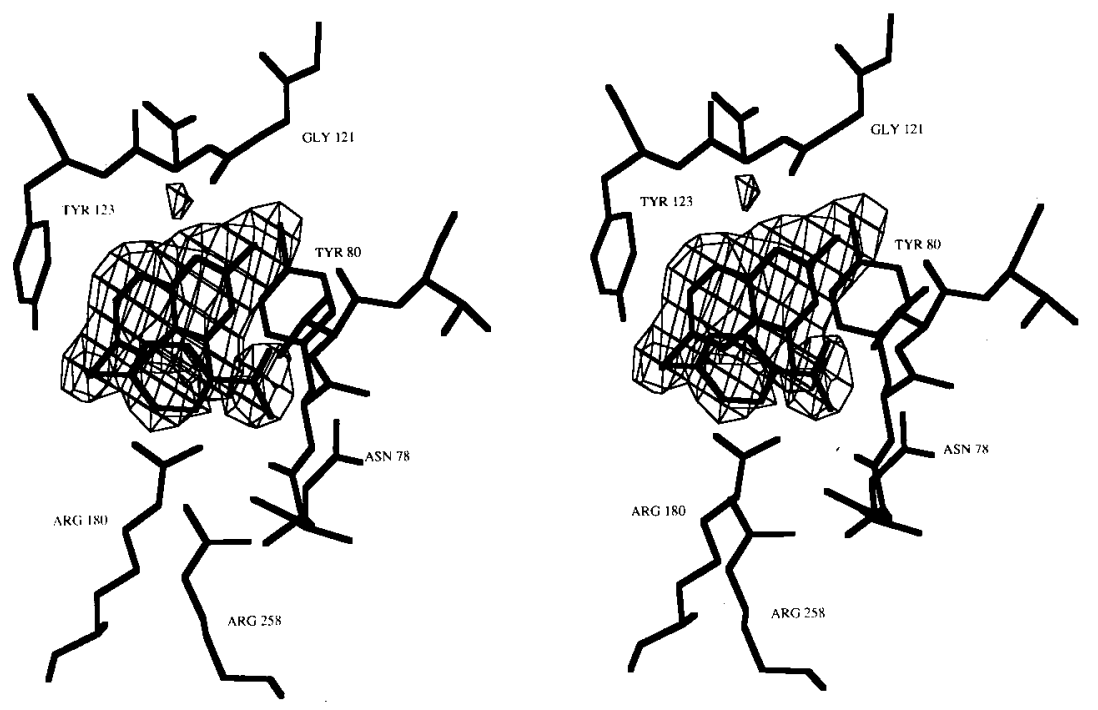

Figure 2. Electron density for pteroic acid complexed to RTA. This is the OMIT density based on $F_{\mathrm{o}}-F_{\mathrm{c}}$ coefficients and phases from the protein model in which Tyr80 has been displaced to form the normal substrate binding site. The difference density baskets are contoured at the $3 \sigma$ level. The refined position of PTA is shown superimposed on the difference density. 
Table 1. Pterin derivatives tested as RTA inhibitors

Pterin (2-amino-6-hydroxypteridine)

Pterin R group

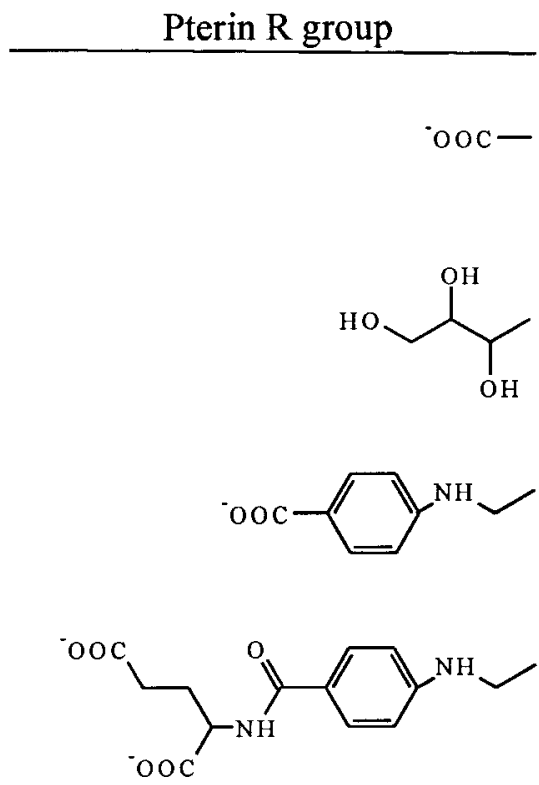<smiles>[R]c1cnc2[nH]c(N)nc(=O)c2n1</smiles>

Compound name

Pterin-6-carboxylic acid

Neopterin

Pteroic acid (PTA)

Folic acid were collected $\left(R_{\text {merge }}=6.6 \%\right)$, the data reduced, and difference Fourier maps calculated. The pterin ring bound in the site previously seen to bind the formycin ring of FMP (Monzingo \& Robertus, 1992) and the pterin ring of PTA as described above. As with PTA and FMP, the side-chain of Tyr80 was displaced by the ligand. Neopterin was positioned by hand, including the propane triol moiety, and XPLOR used to adjust the position of the ligand and the protein in a simulated annealing refinement; the $R$-factor refined to $19.5 \%$ for all data. Coordinates for both the PTA and neopterin complexes have been submitted to the Brookhaven Protein Data Bank and are available from the authors until they have been processed and released.

Neither pterin-6-carboxylic acid nor folic acid acted as inhibitors of RTA within the limits of their solubility. Efforts to soak the compounds into monoclinic crystals even at saturating conditions, and cocrystallization efforts also failed to produce stable complexes for X-ray analysis.

\section{Discussion}

Figure 3 illustrates the interactions between PTA and the active site of RTA. The pterin ring binds in roughly the position of the substrate adenine, sandwiched between the rings of Tyr80 and Tyr123. For comparison, Figure 4 shows a superposition of the formycin ring of FMP (Monzingo \& Robertus, 1992) and the pterin ring of PTA. The $2.6 \AA$ distance between N1 of pterin and the carbo-

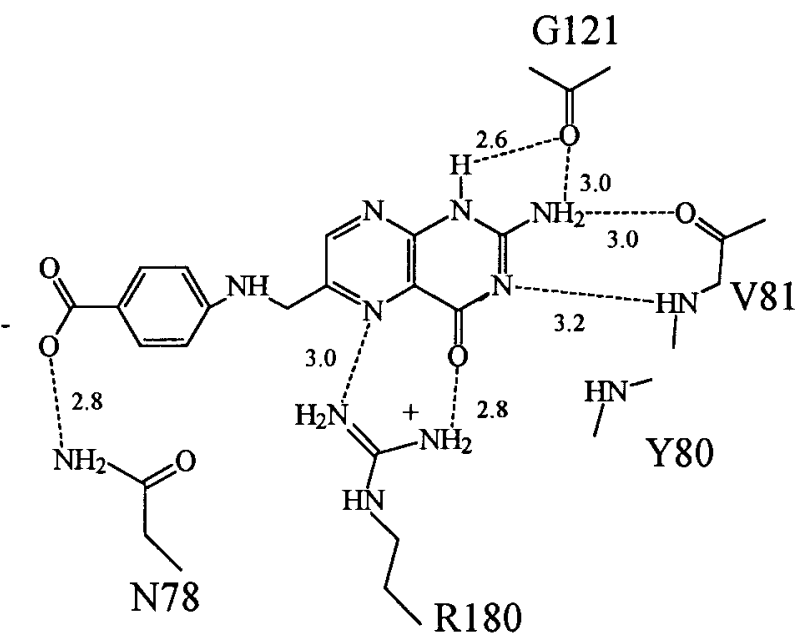

Figure 3. Interactions between pteroic acid and RTA. Hydrogen bonds are shown as broken lines with the lengths indicated. 


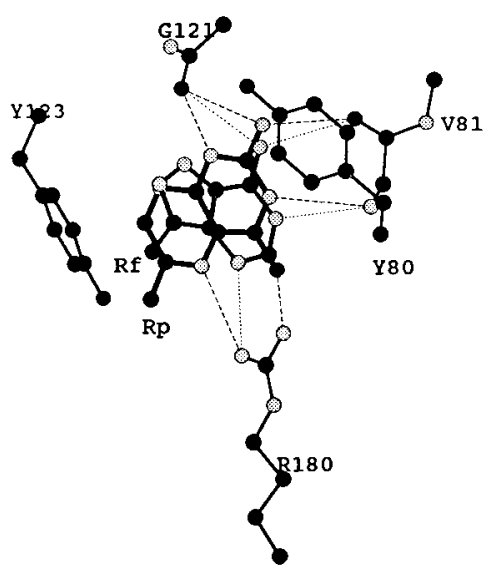

nyl oxygen atom of Gly121 suggests that the pterin is stabilized in a tautomeric form with a hydrogen atom on N1 (shown in Table 1) and this can be donated to the carbonyl group. Note that the 2-amino group of pterin also donates a hydrogen bond to the carbonyl oxygen atoms of Gly121 as well as to Val81; this roughly mimics the role of the 6-amino group on an adenine substrate. In the same way, $\mathrm{N} 3$ of pteroic acid resembles N1 of adenine, receiving a hydrogen bond from the amido $\mathrm{N}$ of Val81. The adenine substrate receives a hydrogen bond at N3 from Arg180, and indeed this is the likely route of substrate protonation in the catalytic mechanism. Pteroic acid receives two hydrogen bonds from Arg180, at the 4-oxo and N5 positions.

The benzoate moiety of PTA bends around the side-chain of Tyr80 and probably makes some nonpolar interactions with it. In fact the benzoate ring appears to bind on the surface of a pocket hypothesized by Monzingo \& Robertus (1992) to be a second recognition site which might accommodate the guanine base of a natural rRNA substrate. Two hydrogen bonds are made to the benzoate group, one between the carboxylate group and Asn78, and one to a water molecule which also bonds Arg258. Although the pterin moiety of PTA makes
Figure 4. Superposition of the formycin and pterin rings in the RTA active site. Carbon atoms are shown filled, nitrogen atoms have a light pattern and oxygen atoms a darker pattern. Hydrogen bonds between PTA and RTA are represented by broken lines and those between FMP and RTA (Monzingo \& Robertus, 1992) by dotted lines. a strong and specific interaction within the adenine recognition site, it seems apparent that the benzoate moiety of PTA is not optimized for interactions within the second site. Modification of this moiety will be a focus for future inhibitor design.

The binding of neopterin to RTA is shown in Figure 5. The orientation of the pterin ring is similar to that seen for PTA. One difference is the bonding of Arg180 to the inhibitor. It bonds to the 4-oxo group of neopterin, but does not bond to N5 as occurs in the PTA complex. Instead a second bond is formed with the proximal hydroxyl of the propane triol moiety. Associated with this rearrangement is a $7^{\circ}$ rotation of the pterin ring. The other atoms of the propane triol moiety of neopterin make no interaction with RTA. Since the propane triol moiety of neopterin is much smaller than the corresponding substituents in PTA, it does not interact with Tyr80 in the same way and appears to lack the van der Waals contribution to binding which might be expected in PTA. This is consistent with energy calculations using SYBYL which show interruption enthalpies between RTA and PTA to be $-106 \mathrm{kcal} / \mathrm{mole}$ and those between RTA and neopterin to be $-73 \mathrm{kcal} /$ mole. Kinetic inhibition data, although not definitive, also suggest
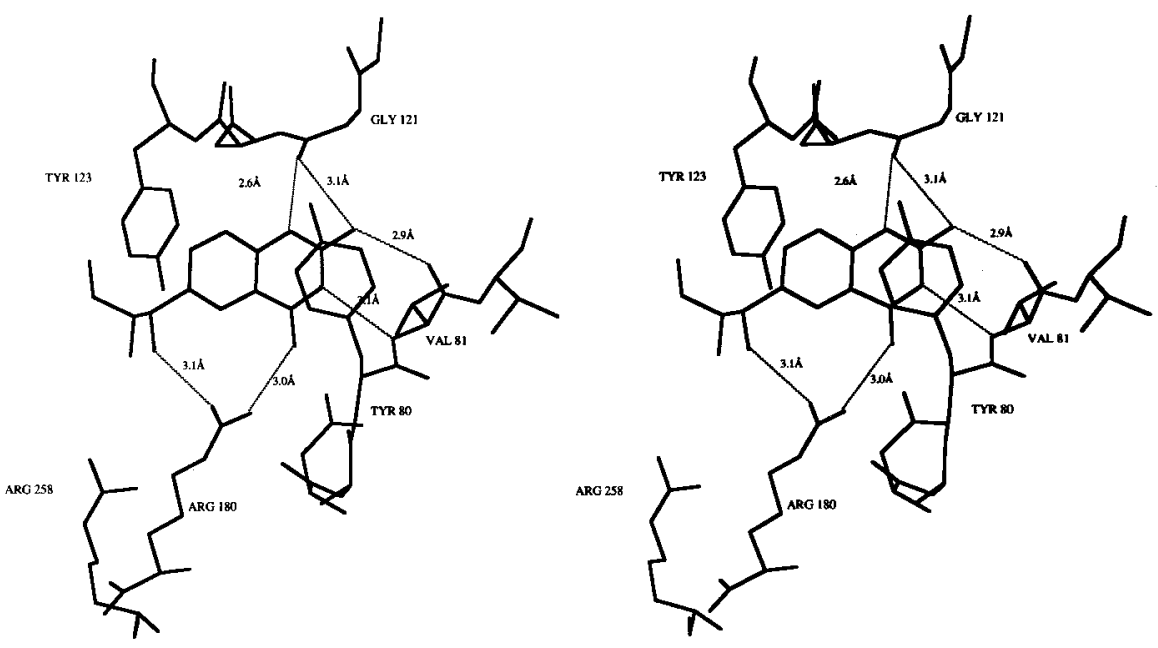

Figure 5. Binding of neopterin in the RTA active site. Hydrogen bonds are shown as broken lines and the lengths are indicated. 
PTA is a better inhibitor and more likely to exhibit tighter binding. The stronger binding of PTA compared with neopterin argues that design of moiety binding to pterin at the 6 position which makes strong and specific interations with RTA will be a profitable approach to creating an efficient inhibitor.

Crystals of RTA-neopterin were isomorphous with native RTA, but crystals of RTA-PTA were reproducibly not isomorphous; RTA-PTA crystals exhibited a contraction of about $3 \AA$ along both the $a$ and $c$ axes. A least-squares superpositioning of the two complexes showed very few significant structural differences between them. The largest changes were at the $\mathrm{N}$ and $\mathrm{C}$ termini, both far removed from the substrate (inhibitor) binding site. The chemical differences between the two inhibitors are centered on the size and charge of the moiety derivatizing pterin at position 6. However, there are no direct interactions of the bound inhibitor with any crystallographically related molecules. Furthermore, the protein conformations itself is very similar in these two active sites, and so it does not appear that inhibitor binding induces protein changes which are then involved directly in crystal packing. It may be that inhibitor binding triggers a series of very subtle changes which propagate throughout the protein and cause a rearrangement of packing, although this seems unlikely. It is also possible that saturating the solution with PTA has an unspecified solvent effect which tends to dehydrate the crystals and causes them to shrink. Except for this phenomenon, the binding of the two inhibitors seems to have roughly the same effect on RTA conformation, moving the Tyr80 side-chain. It seems likely that further inhibitor design can use this observed binding as a foundation and that novel inhibitor models can be fitted to this template without undue concern about predicting protein responses.

Given knowledge of the binding of PTA and neopterin it is possible to rationalize the observation that neither pterin-6-carboxylic acid nor folic acid binds to RTA. Refinement and energy minimization using SYBYL suggested that the interaction enthalpy for pterin-6-carboxylic acid, with one negative charge was low $(-64 \mathrm{kcal} / \mathrm{mole})$ compared with PTA or neopterin. Inspection of the hypothetical binding, assuming that the pterin moiety assumes the position seen in PTA, suggests that the 6 carboxylate is near Glu177 of RTA. Charge repulsion may therefore prevent binding of this simple compound.

Folic acid does not inhibit RTA, nor does it bind to RTA crystals. Folic acid resembles PTA except that the benzoic acid moiety is derivatized with the long and negatively charged glutamic acid. Electrostatic mapping of the RTA surface shows the mouth of the second recognition site, beyond the area binding the PTA benzoate, is generally negative due to the presence of residues like aspartates 75,96 , and 100 . This may repel the folic acid group, driving it into solution and limiting binding compared with PTA.

\section{Materials and Methods}

Recombinant RTA was prepared as described by Ready et al. (1991). RTA activity was measured by its ability to inhibit protein synthesis in an in vitro protein synthesis assay using Artemia salina ribosomes, as described (Ready et al., 1983, 1991). Inhibitor candidates were judged by their ability to disrupt RTA action against the Artemia ribosomes. Pterin compounds including pterin-6carboxylic acid, neopterin, pteroic acid, and folic acid were purchased from the Sigma Chemical Company (St Louis). Concentrations were evaluated spectroscopically, assuming the same ultraviolet spectrum as folic acid, that is $\varepsilon_{283}=25,000$. Because of the limited solubility of the pterins, the ribosome inhibition assays and controls were carried out at $\mathrm{pH} 9$.

Crystals of RTA were grown in the monoclinic form (Robertus et al., 1987; Mlsna et al., 1993) or in a tetragonal form (Weston et al., 1994). Three-dimensional diffraction data were collected on a San Diego Multiwire Systems area detector (Hamlin, 1985) with a Rigaku RU-200 Xray source operating at $50 \mathrm{kV}, 110 \mathrm{~mA}$ with a graphite monochromator. Data were collected using the method of Xuong et al. (1985) and reduced and evaluated using the University of California, San Diego (UCSD) software system (Howard et al., 1985). Rotation and translation searches as well as crystallographic refinement of the RTA inhibitor complex (energy minimization and simulated annealing) were carried out using the X-PLOR package (Brünger, 1988). Molecular modeling was carried out using FRODO (Jones, 1982) running on an Evans and Sutherland PS390.

Molecular modeling programs CHEMX and SYBYL were purchased from Chemical Design Ltd (Oxon, England) and Tripos Inc. (St. Louis), respectively. Interaction energies were calculated with the Tripos force field. The energy minimization was terminated when a 0.05 energy gradient value was reached using the Powell algorithm as implemented in SYBYL. A distance-dependent and a constant function (dielectric constant $=1.5$ ) were used for dielectric effects, with the expectation that the distance-dependent function can simulate the internal protein dielectric, while the constant function simulates the solvent effect on the protein. Non-bonded cutoff was 8.0 A. The net atomic charges used in minimization were from the Kollman method (Weiner et al., 1984) for RTA and from $a b$ initio calculations (6-31 $\mathrm{g}^{* *}$ basis set) for ligands; these were calculated on CRAY YMP and COIL located at the National Institutes of Health.

\section{Acknowledgements}

This work was supported by grant GM 30048 from the National Institutes of Health, by contract number DAMD17-94-C-4006 from the United States Army, and by grants from the Foundation for Research, and the Welch Foundation.

\section{References}

Appelt, K., Bacquet, R. J., Bartlett, C. A., Booth, C. L., Freer, S. T., Fuhry, M. A., Gehring, M. R., Herrmann, S. M., Howland, E. F., Janson, C. A., Jones, T. R., Ken, C. C., Kathardekar, V., Lewis, K. K., Marzoni, G. P., Matthews, D. A., Mohr, C., Moomaw, E. W., Morse, C. A., Oatley, S. J., Ogden, 
R. C., Reddy, M. R., Reich, S. H., Schoettlin, W. S., Smith, W. W., Varney, M. D., Villafranca, J. E., Ward, R. W., Webber, S., Webber, S. E., Welsh, K. M. \& White, J. (1991). Design of enzyme inhibitors using iterative protein crystallographic analysis. J. Med. Chem. 34, 1925-1934.

Brünger, A. T. (1988). Crystallographic refinement by simulated annealing. In Crystallographic Computing 4: Techniques and New Technologies (Isaacs, N. W. \& Taylor, R. R., eds), pp. 126-140, Clarendon Press, Oxford.

de Fiebre, C. (1995). Two convicted of possessing deadly poison. Minneapolis Star-Tribune, March 1, p. 1B.

DesJarlais, R. L., Seibel, G. L., Kuntz, I. D., Furth, P. S., Alvarez, J. C., Ortiz de Montellano, P. R., DeCamp, D. L., Babe, L. M. \& Craik, C. S. (1990). Structurebased design of nonapeptide inhibitors specific for the human immunodeficiency virus 1 protease. Proc. Natl Acad. Sci. USA, 87, 6644-6648.

Ealick, S. E., Babu, Y. S., Bugg, C. E., Erion, M. D., Guida, W. C., Montgomery, J. A. \& Secrist, J. A. (1991). Application of crystallographic and modeling methods in the design of purine nucleoside phosphorylase inhibitors. Proc. Natl Acad. Sci. USA, 88, 11540-11544.

Endo, Y. \& Tsurugi, K. (1987). RNA N-glycosidase activity of ricin A-chain. J. Biol. Chem. 262, 8128-8130.

Frankel, A. E. (ed.) (1988). Immunotoxins. Kluwer Academic Publishers, Boston.

Frankel, A., Welsh, P., Richardson, J. \& Robertus, J. D. (1990). The role of arginine 180 and glutamic acid 177 of ricin toxin A chain in the enzymatic inactivations of ribosomes. Mol. Cell. Biol. 10, 6257-6263.

Goodford, P. J. (1985). A computational procedure for determining energetically favorable binding sites on biologically important macromolecules. J. Med. Chem. 28, 849-857.

Hamlin, R. (1985). Multiwire area X-ray diffractometers. Methods Enzymol. 114, 416-452.

Howard, A. J., Nielsen, C. \& Xoung, N. H. (1985). Software for a diffractometer with multiwire area detector. Methods Enzymol. 114, 453-472.

Huang, Q., Liu, S., Tang, Y., Jin, S. \& Wang, Y. (1995). Studies on crystal structures, active-centre geometry and depurinatig mechanism of two ribosome-inactivating proteins. Biochem. J. 309, 285-298.

Jones, T. A. (1982). FRODO: a graphics fitting program for macromolecules. In Computational Crystallography (Sayre, D., ed.), pp. 303-317, Oxford University Press, Oxford.

Katzin, B. J., Collins, E. J. \& Robertus, J. D. (1991). The structure of ricin A chain at 2.5 A. Proteins: Struct. Funct. Genet. 10, 251-259.

Kim, Y. S. \& Robertus, J. D. (1992). Analysis of several key active site residues of ricin $\mathrm{A}$ chain by mutagenesis and X-ray crystallography. Protein Eng. 5, 775-779.

Kuntz, I. D., Blaney, J. M., Oatley, S. J., Langridge, R. \& Ferrin, T. E. (1982). A geometric approach to macromolecular-ligand interactions. J. Mol. Biol. 161, 269288.

Mlsna, D., Monzingo, A. F., Katzin, B. J., Ernst, S. \& Robertus, J. D. (1993). The structure of recombinant ricin A chain at 2.3 A. Protein Sci. 2, 429-435.
Montfort, W., Villafranca, J. E., Monzingo, A. F., Ernst, S. R., Katzin, B., Rutenber, E., Nuyhen, H. X., Hamlin, R. \& Robertus, J. D. (1987). The threedimensional structure of ricin at $2.8 \AA$. J. Biol. Chem. 262, 5398-5403.

Monzingo, A. F. \& Robertus, J. D. (1992). X-ray analysis of substrate analogs in the ricin A-chain active site. J. Mol. Biol. 227, 1136-1145.

Olsnes, S. \& Pihl, A. (1982). Toxic lectins and related proteins. In The Molecular Action of Toxins and Viruses (Cohen, P. \& Van Heynigen, S., eds), pp. 52-105, Elsevier Biomedical Press, New York.

Ready, M., Bird, S., Rothe, G. \& Robertus, J. D. (1983). Requirements for antiribosomal activity of pokeweed antiviral protein. Biochim. Biophys. Acta, 740, 19-28.

Ready, M. P., Kim, Y. S. \& Robertus, J. D. (1991). Directed alterations of active site residues in ricin $\mathrm{A}$ chain and implications for the mechanism of action. Proteins: Struct. Funct. Genet. 10, 270-278.

Remnick, D. (1992). KGB plot to assassinate Solzhenitzen reported. Washington Post, April 21, p. D1.

Ren, J., Wang, Y., Dong, Y. \& Stuart, D. I. (1994). The $\mathrm{N}$-glycosidase mechanism of ribosome-inactivating proteins implied by crystal structures of alphamomorcharin. Structure, 2, 7-16.

Rich, V. (1992). Murderous experiments of Stalin's police chief. New Scientist, 135, 8.

Robertus, J. D., Piatak, M., Ferris, R. \& Houston, L. L. (1987). Crystallization of ricin A chain obtained from a cloned gene expressed in Escherichia coli. J. Biol. Chem. 262, 19-20.

Rutenber, E. \& Robertus, J. D. (1991). The structure of ricin B chain at $2.5 \AA$ resolution. Proteins: Struct. Funct. Genet. 10, 260-269.

Rutenber, E., Katzin, B. J., Collins, E. J., Mlsna, D., Ernst, S. E., Ready, M. P. \& Robertus, J. D. (1991). The crystallographic refinement of ricin at $2.5 \AA$ resolution. Proteins: Struct. Funct. Genet. 10, 240-250.

Schlossman, D., Withers, D., Welsh, P., Alexander, A., Robertus, J. D. \& Frankel, A. (1989). Expression and characterization of mutants of ricin toxin A chain in Escherichia coli. Mol. Cell. Biol. 9, 5012-5021.

von Itzstein, M., Wu, W. Y., Kok, G. B., Pegg, M. S., Dyason, J. C., Jin, B., Van Phan, T., Smythe, M. L., White, H. F., Oliver, S. W., Colman, P. M., Varghese, J. N., Ryan, D. M., Woods, J. M., Bethell, R. C., Hotham, V. J., Cameron, J. M. \& Penn, C. R. (1993). Rational design of potent sialidase-based inhibitors of influenza virus replication. Nature, 363, 418-423.

Weiner, S. J., Kollman, P. A., Case, D. A., Singh, U. C., Ghio, C. G., Alagona, G. S., Profeta, S. \& Weiner, P. (1984). A new force field for molecular mechanical simulation of nucleic acids and proteins. J. Am. Chem. Soc. 106, 765-784.

Weston, S. A., Tucker, A. D., Thatcher, D. R., Derbyshire, D. J. \& Pauptit, R. A. (1994). X-ray structure of recombinant ricin A-chain at $1.8 \AA$ resolution. J. Mol. Biol. 244, 410-422.

Xuong, N. H., Nielson, C., Hamlin, R. \& Anderson, D. (1985). Strategies for data collection from protein crystals using a multiwire counter area detector diffractometer. J. Appl. Crystallog. 18, 342-350. 